\title{
SAÚDE E SOCIEDADE
}

\section{Carta ao Editor}

O processo de escrita científica e a consolidação da atitude crítica no âmbito acadêmico e profissional da medicina

The process of scientific writing and the consolidation of critical attitude in the academic and professional fields

El proceso de redacción científica y la consolidación de uma actitud crítica em el ámbito académico y professional de la medicina

José Wilson Batista da Silva Júnior'1, ORCID: https://orcid.org/0000-0002-4253-5738 Débora Teixeira Viana1, ORCID: https://orcid.org/0000-0002-1577-2076

Maria Deysiane Porto Araujo², ORCID: https://orcid.org/0000-0002-1258-0845

${ }^{1}$ Graduanda em Medicina na Universidade Federal de Alagoas (UFAL), campus Arapiraca, Alagoas, Brasil.

2 Professora do Curso de Medicina na Universidade Federal de Alagoas (UFAL), campus Arapiraca. Alagoas, Brasil.

\section{Caro editor,}

O processo de aquisição de saberes mostrou-se importante para a sobrevivência da espécie humana e nos traz características singulares nas quais pode-se assentar uma base sólida de conhecimento (1). Diante dessa perspectiva, a escrita científica mostra-se como pilar para a progressão do raciocínio apurado e crítico necessário para uma boa conduta clínica de modo que o estímulo à pesquisa, à experimentação e ao entendimento dos processos estatísticos que advém dos novos tratamentos e diagnósticos são indispensáveis para que a profissão médica seja exercida em sua plenitude (2).

A importância de se estimular atitudes pautadas em fatos que possuam evidência científica também constitui um forte fator indutor para o contato técnico dos alunos de graduação, em especial os de medicina, com o conhecimento. As condutas dos profissionais com formação acadêmica voltada para um equilibro entre práticas científicas e procedimentais mostram-se calcadas em fatos concretos e evidências ao invés de se levar consideração saberes que, com um bom tratamento estatístico, poderiam ser demonstrados equivocados (3). Nesse sentido, há de se ter em mente que o senso comum pode, sim, ser detentor de ciência, a partir do momento em que pode servir como indicador para a investigação e, desse modo, uma posterior confirmação de que se tem, de fato, base ou não para continuar a existir, porém, esse apuramento mais criterioso só é possível para profissionais que tenham a capacidade de analisar os dados (4).

Ciências de saúde, como a epidemiologia, possuem necessidades intrínsecas do conhecimento experimental, pautados em processos estatísticos(5), que seriam supridos com uma maior inserção dos alunos de graduação, desde os primeiros períodos, em programas de iniciação científica ou de extensão e em disciplinas de metodologia científicas, nas quais se fosse proposto a escrita de seus resultados em periódicos para que fosse exercitado o ato de escrever de acordo com as normas e categorias solicitadas pelas revistas escolhidas(6).

Outro ponto importante está relacionado à confiança adquirida pelos discentes nas práticas futuras, quando contemplados com o raciocínio metodológico e científico durante a graduação. A chamada autoeficácia, termo que se refere à confiança que o aluno tem em realizar alguma atividade, aumenta quando o aluno está inserido em metodologias ativas de ensino, como o PBL (Problem Based Learning) ou TBL (Team Based Learning), o que leva a conclusão de que a proposição de problemas científicos e sua tentativa de resolução causa nos graduandos uma característica mais proativa e segura (7).

Além da questão da ciência natural, como a medicina é muito conhecida, deve-se ter em mente, também, que a medicina abriga uma forte ligação com as humanidades e que a documentação científica vai além de dados quantitativos analisados por um tratamento matemático mais avançado. A questão dos relatos de caso e histórias médicas também serve como construtor de sabedoria para os praticantes da profissão, de maneira que haja uma maior compreensão do seu papel sociopolítico como transformador de sua comunidade (8).

Percebe-se, por fim, que um entendimento sobre o que seria ciência, seu processo gerador e perpetuação, leva os estudantes a um caminho de busca do aprimoramento da capacidade de elaborar um senso crítico baseado no saber científico e, para que isso ocorra, se torna de extrema importância que haja o contato do acadêmico com as variáveis que os possibilitem tal interação na Universidade. É, assim, que este texto recomenda aos acadêmicos dos primeiros períodos do curso de medicina procurarem por programas como os de Iniciação Científica, e propõe, também, a observância e adesão das Universidades a grades curriculares voltadas para a metodologia científica, tão importantes no desempenho profissional futuro. Um discente que possua ampla consciência do processo científico estará mais apto a dar um diagnóstico preciso e realizar um tratamento mais adequado a seu paciente (2, $3,6)$.

\section{REFERÊNCIAS}

1. Morais Junior, VP. A complexidade homo e a revolução cognitiva. Rev. Seara Filosófica, n. 18, p. 01-13, 2019. Disponível em: https:// periodicos.ufpel.edu.br/ojs2/index.php/searafilosofica/article/ view/14850 
2. Pirola, SBFB et al. A importância da Iniciação Científica na graduação de Medicina. Rev. Corpus Hippocraticum, v. 1, n. 1, 2020. Disponível em: http://189.112.117.16/index.php/revista-medicina/article/view/232

3. Atallah, AN. Medicina baseada em evidências. Diagn Tratamento, v. 23 , n. 2, p. 43-4, 2018. Disponível em: http://www. associacaopaulistamedicina.org.br/assets/uploads/old/revista $\mathrm{rdt} / 3633 \mathrm{~b} 0 \mathrm{e} 2 \mathrm{~b} 787 \mathrm{dc55a3433cda35f10dfc.pdf \# page=5}$

4. Cabral, CC John Dewey sobre ciência e senso comum: semelhanças e dessemelhanças. Cognitio-Estudos: rev. eletrônica de filosofia, v. 15 , n. 1 , p. $40-9,2018$. Doi: https://doi.org/10.23925/18098428.2018v15i1p40-49

5. Sousa, A. Estatística, estudos epidemiológicos, ensaios clínicos e planeamento do sistema de saúde. Correio dos Açores, p. 17-7, 2019. Disponivel em: http://hdl.handle.net/10400.3/5362

6. Da Rocha, LB et al. Scientific initiation in medicine course: contributions and challenges. Braz. J. Hea. Rev., v. 2, n. 6, p. 5445-5456, 2019. Doi: https://doi.org/10.34119/bjhrv2n6-046

7. Baptista, CCTN et al. Challenges of teaching in a Medical course: analysis of the pillars of resilience. Rev. Docência Ensino Super., v. 11, p. 1-20, 2021. Doi: https://doi.org/10.35699/2237-5864.2021.22175

8. De Passos, VBC et al. Atendimento humanizado: as concepções de estudantes de Medicina. ver. Bras. Promoç. Saúde., v. 33, 2020. Doi: $10.5020 / 18061230$

\section{Como citar}

Silva Junior, JWB, Viana, DT, Araújo, MDP. O processo de escrita científica e a consolidação da atitude crítica no âmbito acadêmico e profissional da medicina. Revista Portal: Saúde e Sociedade, 6 (único):e02106019. DOI:10.28998/rpss.e02106019.

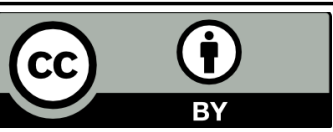

Esse é um artigo de Acesso Aberto distribuído sob os termos do Creative Commons Attribution License, que permite irrestrito uso, distribuiçõa e reprodução em qualquer meio, desde que o trabalho seja devidamente citado. 